ARTICLE

\title{
A Whole Body Counting Experience on the Internal Contamination of Iodine-131 at a Korean Nuclear Power Plant
}

\author{
Tae Young KONG* ${ }^{*}$ Hee Geun KIM \\ Korea Electric Power Research Institute, 103-16 Munji-dong, Yuseong-gu, Daejeon, 305-380, Korea
}

\begin{abstract}
During a maintenance period at a Korean nuclear power plant, internal exposure of radiation workers occurred by the inhalation of ${ }^{131} \mathrm{I}$ released into the reactor building from a primary system opening. The internal radioactivity measurements of the radiation workers contaminated by ${ }^{131}$ I were immediately conducted using a whole body counter and whole body counting was performed again a few days later. In this study, the intake calculated by hand, based on both the entrance records to radiation controlled areas and the measurement results of the air concentration for ${ }^{131}$ I in these areas were compared with the results of whole body counting. As a result, it was concluded that the intake estimation using both whole body counting and air sampling provided similar results.
\end{abstract}

\section{KEYWORDS: ${ }^{131}$ I, internal exposure, whole body counting, radioactive concentration in air, intake estimation}

\section{Introduction}

The total amount of radiation exposure to workers in Korean nuclear power plants (NPPs) increased at the beginning of NPP commercial operation due to the lack of operation experience and an increase in the number of NPP units. Since 2000, however, it has been maintained at a stable situation or decreased gradually despite an increase in the number of operating NPP units. ${ }^{1)}$ In particular, the amount of internal exposure accounts for only $7 \%$ of total exposure. Most internal exposures are attributed to occurrences at pressurized heavy water reactors (PHWRs) due to an intake of tritium, approximately $99 \%$, and the portion of internal exposure by gamma emitters including ${ }^{58} \mathrm{Co},{ }^{60} \mathrm{Co},{ }^{131} \mathrm{I},{ }^{95} \mathrm{Nb}$, and ${ }^{54} \mathrm{Mn}$, which account for less than $1 \%{ }^{2)}$

During the maintenance period of Ulchin NPPs unit 3 in Korea in 2002, radioactive materials were released into the air inside the reactor building when the primary system was opening. Thus, a number of workers inside the reactor building were contaminated by the inhalation of ${ }^{131} \mathrm{I} .{ }^{3,4)}$ After withdrawal from the work place, portal monitoring indicated that they were contaminated by radioactive materials, and then their skin was monitored first. After an examination of external contamination, they took a whole body counting to monitor internal exposure. As a result, it was found that a lot of the radiation workers had internal exposure to ${ }^{131} \mathrm{I} .{ }^{3,4)}$

In initial measures, health physicists did not completely understand iodine metabolism and operating characteristics of a whole body counter (WBC) and these caused some mistakes during the whole body counting. Some workers who took several repeated counts right after contamination showed different radioactivity depending on the time of the whole body counting although they did not have any additional contamination. In addition, whole body counting resulted in no internal exposure for some workers who had several showers and facial washings and for some workers who took

*Corresponding Author, Tel. +82-42-865-5480, FAX.

+82-42-865-5412, E-mail: eagertae@kepri.re.kr counting again the next day, which were a simple external contamination.

This paper describes the experiences learned through whole body counting and the estimation of the intake after ${ }^{131}$ I contamination at Ulchin NPPs unit 3 during the maintenance period. The intake calculated by hand, based on both the entrance records to radiation control areas and the measurement results of air sampling for ${ }^{131} \mathrm{I}$ in these areas, was compared with the results of whole body counting.

\section{Internal Dose Monitoring Programs}

In general, in order to monitor internal exposure caused by gamma emitters, a whole body counter (WBC) is used in NPPs. All Korean NPPs are equipped with several WBCs to monitor the likelihood of internal exposure of workers. Whole body counting is usually conducted every year after initial counting for enrollment in radiation workers. ${ }^{5)}$ In addition, whole body counting is carried out after the performance of specific tasks where the inhalation or intake of radioisotopes might be expected. In particular, all NPP workers are required to receive whole body counting before and after periodical maintenance.

The WBC utilized for whole body counting in Korean NPPs is the vertical linear Fastscan (Model 2250) manufactured by Canberra Inc., which is used for in vivo measurements of radionuclides with energies from $300 \mathrm{keV}$ to $1.8 \mathrm{MeV} .^{6)}$ This WBC system consists of two large sodium iodide detectors $(7.6 \times 12.7 \times 40.6 \mathrm{~cm})$, which typically provides an a priori lower limit of detection (LLD) of about $150 \mathrm{~Bq}$ for ${ }^{60} \mathrm{Co}$ with a count time of one minute for a normal person containing ${ }^{40} \mathrm{~K}$. Additionally, WBCs which have high purity germanium (HPGe) detectors are also equipped in each NPP site, which adopts the horizontal linear bed-type geometry. Fig. 1 displays two WBCs in Korean NPPs.

A WBC provides four geometries that adjust the detector's efficiency depending on the area of the body where the radionuclides were deposited to measure the exact activity inside the body of a worker. In Korean NPPs, efficiency 
calibrations of WBCs for all geometries (whole body, thyroid, lungs, and gastrointestinal (GI) tract) are normally conducted every six months or every year using a humanoid or calibration phantom. After calibration, results are reported to check the performance and mechanical conditions of each WBC based on the guidance of ANSI N 13.30.7)

In a CANDU reactor, workers have access to radiation controlled areas where tritium is in the air and where they are likely to have internal exposure by tritium inhalation. Thus, workers submit urine samples to health physicists after radiation work for an internal dose assessment by tritium. In Korean NPPs, a liquid scintillation counter (LSC) is typically used to measure the tritium concentration in urine samples of radiation workers after mixing with scintillation cocktails.

\section{Release of Iodine-131 and Internal Exposure}

Ulchin NPPs unit 3, the Korean standard nuclear power plant (KSNP) generating 1,000 MWe, reached the first critical state in December 1997 and has been in commercial operation since August 1998. For the fourth periodic maintenance, the reactor was shut down at the end of 2002, and then the steam generator manway was opened to access. Most radiation workers who accessed the reactor building were contaminated internally by ${ }^{131}$ I. Table 1 shows the timeline of ${ }^{131}$ I release and internal exposure. ${ }^{4)}$

Table 1 Timeline of ${ }^{131}$ I release and internal exposure at Ulchin NPPs unit 3

\begin{tabular}{ll}
\hline Date \& Time & Events \\
\hline Nov. 23, 2002 & $\begin{array}{l}\text { Beginning of the 4th periodic } \\
\text { maintenance }\end{array}$ \\
Nov. 28, 2002 01:40-04:40 & $\begin{array}{l}\text { Detensioning of stud bolt at } \\
\text { nuclear reactor head } \\
\text { Manway opening of steam } \\
\text { geverator }\end{array}$ \\
Nov. 28, 2002 02:20-03:45 05:15 & $\begin{array}{l}\text { Occurrence of contamination } \\
\text { during withdrawal of workers for } \\
\text { manway opening task }\end{array}$ \\
Complete withdrawal of workers \\
Nov. 28, 2002 07:20 & $\begin{array}{l}\text { inside the reactor building } \\
\text { Restart of maintenance inside the } \\
\text { reactor building } \\
\text { Whole body counting and } \\
\text { internal dosimetry (continued } \\
\text { after that time) } \\
\text { Suspension of maintenance inside } \\
\text { the reactor building } \\
\text { Restart of maintenance inside the } \\
\text { Nov. 28, 2002 12:00 }\end{array}$ \\
reactor building \\
\hline
\end{tabular}

The airborne radioactivity of the primary system at Ulchin NPPs unit 3 had been kept increased because of a defect of nuclear fuels during the fourth operation period. ${ }^{4)}$ Thus, ${ }^{131} \mathrm{I}$ was released into the air inside the reactor building when the primary system was opening and the airborne radioactivity inside the reactor building increased. After that, radiation monitors sounded an alarm and all workers who participated in the maintenance inside the reactor building were withdrawn with a suspension of maintenance. However, a number of workers inside the reactor building were contaminated by the inhalation of ${ }^{131} \mathrm{I}$. This was attributed to the fact that the radioactivity of ${ }^{131} \mathrm{I}$ was increased by the volatilization during the steam generator manway opening, but the volatilization velocity of iodine in the reactor coolant system was faster than expected and the withdrawal of radiation workers from the reactor building was delayed since it took time for the iodine sampling and radionuclide analysis in the air of the reactor building. ${ }^{4}$

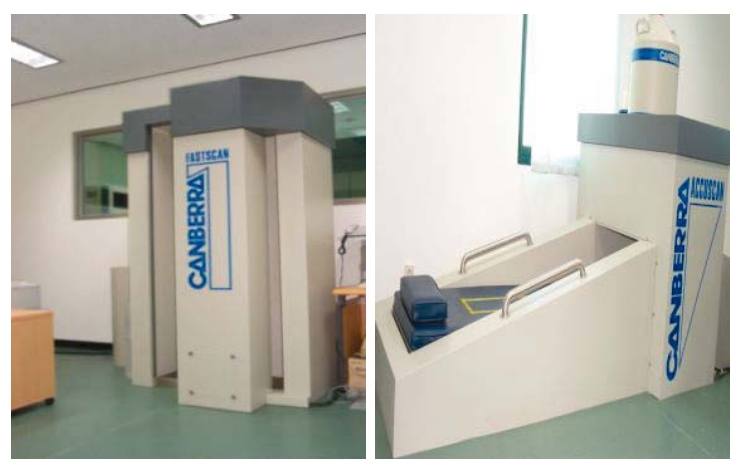

Fig. 1 Whole body counters in Korean NPPs

\section{IV. ${ }^{131}$ I Characteristics and Whole Body Countings}

According to the technical guidance from the International Commission on Radiological Protection (ICRP) and technical reports or papers, iodine is classified as a radionuclide which is difficult to measure and to estimate internal exposure. ${ }^{8)}$ In particular, iodine inside the body is fast to be absorbed into organs and to excrete from organs. Some are concentrated at thyroid and then removed because of its high volatility and chemical characteristics. ${ }^{8,9,10)}$ Thus, whole body counting for the inhalation of iodine is difficult and it results in some errors in counting. To prevent this error, the United States Nuclear Regulatory Commission (USNRC) recommends a bioassay with a lapse of a specific time after inhalation of ${ }^{131} \mathrm{I}^{9 \text { ) }}$

In 2002 , the release of ${ }^{131} \mathrm{I}$ into the air inside a reactor building occurred; whole body counting for radiation workers contaminated by ${ }^{131} \mathrm{I}$ was immediately conducted using whole body geometry. ${ }^{11-13)}$ However, since whole body counting was conducted right after the inhalation of ${ }^{131} \mathrm{I}$, some workers who took several repeated counts showed different radioactivity depending on the time of the whole body counting although they did not have any additional contamination. In addition, whole body counting resulted in no internal exposure for some workers who had several showers and facial washings and for some workers who took counting again the next day, which were a simple external contamination.,11-13) Thus, to check the performance and calibration of the WBC, re-countings were conducted using 
other WBCs of both vertical linear and horizontal linear geometry, which belong to other NPPs, for workers contaminated by ${ }^{131} \mathrm{I}$. As a result, the detected activity was similar with previous ones and it confirmed that the performance and calibration of the WBC are normal., ${ }^{3,11-13)}$

In general, reliable detected internal activity can be obtained for whole body counting when counting is conducted with the lapse of a specific time after intake of radioactive materials. However, for internal contamination of ${ }^{131}$ I at Ulchin NPPs, whole body counting for workers was conducted right after withdrawal from the reactor building; thus, whole body counting was conducted before equilibrium of iodine activity inside the body. The earliest counting was done 3 hours after the intake of iodine., ${ }^{3,11-13)}$ The reason for whole body counting right after is that it is possible to manage the radiation safety efficiently because there are a lot of simultaneous tasks and some workers put into various tasks during the maintenance period.

The whole body counting was performed again 2 or 3 days after the inhalation of ${ }^{131}$ I for all contaminated workers in consideration of the deviation of detected activity. In this case, both the thyroid and whole body geometries were used for whole body counting, but for intake estimation, the detected internal activity from the whole body geometry, which provided more conservative results, was used. There was a likelihood of overestimating the intake of the detected internal activity from the whole body geometry, but it was regarded that the risk for radiation management was very low because the deposited radionuclide and its deposited location was not known and the detected internal activity was lower than annual dose limits. In particular, whole body counting has been used as a measure to prove that a work place is not contaminated by radioactive materials rather than to monitor and measure the internal activity in Korean NPPs; thus, the risk of selection of whole body geometry is trivial for intake estimation.

According to ICRP publications 54 and 78 for guidance of internal dosimetry, the activity of ${ }^{131} \mathrm{I}$ after inhalation increases rapidly until 1 or 2 days after inhalation, and then its activity decreases gradually. ${ }^{8,10)}$ Thus, it was concluded that 1 or 2 days after the inhalation of ${ }^{131} \mathrm{I}$ is the time that the activity of ${ }^{131} \mathrm{I}$ inside the body reaches equilibrium and it becomes possible to do a steady whole body counting. Basically, intake estimation using whole body geometry should use the Intake Retention Fraction (IRF) for the whole body, but ICRP reports do not provide the IRF for the whole body; thus the IRF for thyroid was used for intake estimation. ${ }^{8,10)}$ In this case, it was confirmed that the IRFs for thyroid and whole body are different for intake estimation in the short time after inhalation of ${ }^{131} \mathrm{I}$, but a few days after the inhalation of ${ }^{131} \mathrm{I}$, the IRFs for thyroid and whole body become the almost same and this makes no difference of intake estimation of ${ }^{131} \mathrm{I}$ after a few days of inhalation. Table 2 shows representative 10 detected activities of whole body counting for inhalation of ${ }^{131} \mathrm{I} \mathrm{I}^{3,12,13)}$ As a result of internal dose assessment using these data, it was found that maximum effective dose was $0.76 \mathrm{mSv} .{ }^{12,13)}$
Table 2 Whole body counting for inhalation of ${ }^{131} \mathrm{I}$

\begin{tabular}{cccccc}
\hline \multicolumn{5}{c}{ Whole body counting } \\
\cline { 2 - 6 } No. & $\begin{array}{c}\text { Initial } \\
\text { count } \\
(\mathrm{Bq})\end{array}$ & $\begin{array}{c}\text { Time after } \\
\text { intake } \\
(\text { Days })\end{array}$ & $\begin{array}{c}\text { Time after } \\
\text { intake } \\
(\text { Hours })\end{array}$ & $\begin{array}{c}\text { Recount } \\
(\mathrm{Bq})\end{array}$ & $\begin{array}{c}\text { Time after } \\
\text { intake } \\
(\text { Days })\end{array}$ \\
\hline 1 & 7,092 & 1.47 & - & 2,149 & 12.62 \\
2 & 10,420 & 0.50 & 12 & 2,670 & 10.39 \\
3 & 2,667 & 0.22 & 5.3 & 2,515 & 12.22 \\
4 & 12,330 & 0.39 & 9.3 & 4,563 & 12.46 \\
5 & 8,244 & 1.21 & - & 2,458 & 12.27 \\
6 & 4,819 & 0.23 & 5.5 & 2,177 & 11.43 \\
7 & 5,775 & 1.2 & - & 2,408 & 12.30 \\
8 & 13,170 & 0.57 & 13.7 & 2,490 & 11.86 \\
9 & 5,556 & 0.31 & 7.4 & 5,786 & 12.60 \\
10 & 1,548 & 0.41 & 9.8 & 984 & 9.38 \\
\hline
\end{tabular}

\section{Intake Estimation by Air Concentration}

The reliability of the initial detected activity which resulted from whole body counting in the short time after inhalation of ${ }^{131} \mathrm{I}$ was reviewed. The airborne concentration of the reactor building had been kept about $1 \times 10^{-2} \mathrm{~Bq} / \mathrm{cc}$ for ${ }^{131}$ I during the approximately 3 days after the steam generator manway opening. This airborne concentration was the result of the measurement of ${ }^{131} \mathrm{I}$ in the air and Fig. 2 shows the trend of airborne concentration of ${ }^{131} \mathrm{I}$ after the primary system opening. In particular, iodine has a characteristic that it diffuses uniformly in the air because it has high volatility.

In addition, 2 workers who participated in the maintenance at the reactor building did not stay at a specific place but went around the reactor building for inspection. Thus, it was concluded that if the average airborne concentration of ${ }^{131} \mathrm{I}$ used for intake estimation for them, the difference of airborne concentration at each area of the reactor building could be disregarded. The amount of their respiration was calculated by the record of entrance and exit for the reactor building, which shows a total of 90 minutes: 25 minutes on November 28, 2002, and 65 minutes on November 29, 2002. In this case, the coefficient for protection of the respiratory device was not applied for the intake estimation. Intake using the airborne concentration of ${ }^{131}$ I was calculated as Eq. (1).

Intake $=$ Airborne concentration of ${ }^{131} \mathrm{I}$

$\times$ Respiration rates of reference man

$\times$ Length of stay inside workplace by entrance record

$=\frac{1 \times 10^{-2} B q}{c c} \times \frac{1.2 m^{3}}{h r} \times \frac{10^{6} c c}{m^{3}} \times \frac{1 h r}{60 \mathrm{~min}} \times(25+65) \mathrm{min}$

$=1.84 \times 10^{4} B q$ 


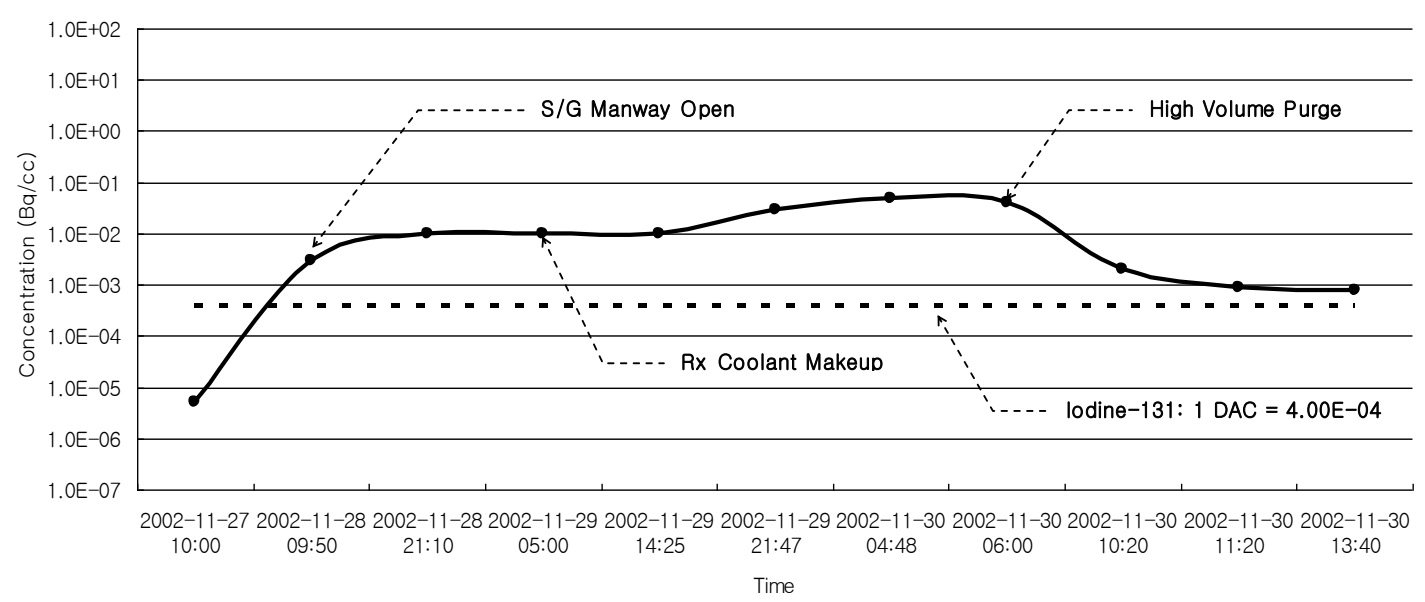

Fig. 2 Trend of airborne concentration of ${ }^{131} \mathrm{I}$ after primary system opening

Intakes of ${ }^{131} \mathrm{I}$ resulting from whole body counting showed $1.82 \times 10^{4} \mathrm{~Bq}$ and $1.32 \times 10^{4} \mathrm{~Bq}$, respectively, and it showed approximately a maximum $30 \%$ difference with the hand calculation results. Thus, the results of intake estimation using both whole body counting and hand calculation with airborne concentration coincided with each other relatively. ${ }^{3)}$

\section{Conclusion}

During the maintenance period of Ulchin NPPs unit 3 in 2002, radioactive materials were released into the air inside the reactor building when the primary system was opening. This resulted in a number of workers inside the reactor building being contaminated by the inhalation of ${ }^{131} \mathrm{I}$. In order to detect the internal activity inside the workers, whole body counting was conducted right after the inhalation of ${ }^{131} \mathrm{I}$, but several trial and errors were experienced because of a lack of understanding of the characteristics of WBC and the complexity of ${ }^{131}$ I metabolism.

Despite the confusion for internal dosimetry at the initial stage, the criteria for intake estimation and whole body counting for ${ }^{131} \mathrm{I}$ was investigated and the method of whole body counting was quickly and appropriately determined. Recounts of whole body counting after several days, which are taken for reaching ${ }^{131} \mathrm{I}$ equilibrium, were conducted and the final intake was determined. In this process, the detected activity was confirmed using other WBCs which belong to other NPPs and intake was calculated manually using the airborne concentration of ${ }^{131} \mathrm{I}$ based on the record of entrance and exit for the reactor building. Finally, it was confirmed that the results of the intake estimation using both whole body counting and hand calculation with airborne concentration coincided with each other relatively.

\section{Acknowledgment}

This research was carried out with the financial support of Korea Hydro \& Nuclear Power Corporation.

\section{References}

1) Korean Hydro \& Nuclear Power Corporation, 2007 annual report for the radiation safety management in nuclear power plants, (2007).

2) Korean Hydro \& Nuclear Power Corporation, Final report for development on the verification system of internal dose measurement and assessment, I05NJ14, (2006).

3) H. G. Kim. "Investigation of internal dose assessment method for inhalation of ${ }^{131}$ I," Proc. of 2003 KINS Radiation Safety Symposium, Seoul, (2003).

4) Korean Hydro \& Nuclear Power Corporation. Guide for radiation safety manager, Rev. 21, (2005).

5) Korea Hydro \& Nuclear Power Corporation. Standard procedure for nuclear power plants - internal dose assessment, Radiation-06, (2003).

6) Canberra Inc., Model 2250 Fastscan high-throughput whole body counter, Brochure of Canberra's whole body counting system,(2002).

7) American National Standard Institute, Performance Criteria for Radiobioassay, ANSI HPS N13.30, (1996).

8) International Commission on Radiological Protection, Individual Monitoring for Internal Exposure of Workers Replacement of ICRP Publication 54, ICRP Publication 78. (1997).

9) United States Nuclear Regulatory Commission, Regulatory Guide 8.20: Application of Bioassay for I-125 and I-131, USNRC, (1979).

10) International Commission on Radiological Protection, Individual Monitoring for Intakes of radionuclides by Workers: Design and Interpretation, ICRP Publication 54. (1987).

11) H. G. Kim, T. Y. Kong, "The Intakes and Committed Effective Dose from Internally Deposited Iodine-131 due to an Internal Contamination Event of Ulchin NPPs in Korea - Experiences and Lessons Learnt," J. Nuclear Science and Technology, Supplement 5, 194-196 (2008).

12) H. G. Kim, T. Y. Kong, "The Whole Body Counting Experience on the Internal Contamination of ${ }^{131} \mathrm{I}$ at Korean Nuclear Power Plants," J. Radiation Protection, 34[3], 121-128 (2009).

13) H. G. Kim, T. Y. Kong, "The Experience on Intake Estimation and Internal Dose Assessment by Inhalation of Iodine-131 at Korean Nuclear Power Plants," J. Radiation Protection, 34[3], 129-136 (2009). 